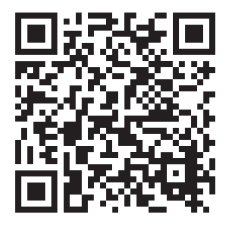

\section{Inmunodeficiencia combinada grave: informe de caso}

\author{
Dr. José Guillermo Murguía Pérez, ${ }^{\star}$ Dr. Giordano Pérez-Gaxiola, ${ }^{\ddagger}$ \\ Dr. Miguel García-Domínguez ${ }^{\S}$
}

\section{RESUMEN}

Introducción: La inmunodeficiencia combinada grave se caracteriza por defecto inmunológico, debido a linfopenia de células $T$, con o sin deficiencia de células B y células NK, provocando infecciones graves y de inicio temprano en la vida por agentes oportunistas como hongos, bacterias y/o virus, representando una emergencia pediátrica. Reporte de caso: Presentamos el caso de un paciente masculino que a los dos meses de edad presentó fiebre persistente, linfopenia y ausencia de sombra tímica en la radiografía de tórax; además, se integró el diagnóstico de inmunodeficiencia combinada grave con niveles de inmunoglobulinas bajos, tamiz metabólico neonatal ampliado con cuantificación de círculos de escisión del receptor de células T (TREC's) y subpoblaciones de linfocitos bajos. Se estableció tratamiento con gammaglobulina intravenosa y recibió trasplante de células progenitoras hematopoyéticas, lo cual fracasó por infección viral enteral crónica y falleció posterior a sepsis gastrointestinal con choque séptico. Conclusión: La presentación temprana y gravedad de síntomas deben hacer la sospecha para un diagnóstico y tratamiento oportuno, con un impacto directo en el pronóstico y calidad de vida.

Palabras clave: Inmunodeficiencia combinada grave, círculos de escisión del receptor de células T, linfopenia.

\section{ABSTRACT}

Introduction: Severe combined immunodeficiency is characterized by immunological defect due to T-cell lymphopenia, with or without B-cell and NK-cell deficiency, causing serious infections and early onset by opportunistic agents such as fungi, bacteria and/or virus, representing a pediatric emergency. Case report: We present the case of a male patient who at two months of age presented persistent fever, lymphopenia and absence of thymic shadow on the chest radiograph in which the diagnosis of severe combined immunodeficiency was integrated due to low immunoglobulin levels, expanded metabolic neonatal sieve with quantification of T-cell receptor excision circles and subpopulations of T-lymphocytes, treatment with intravenous gammaglobulin was established and he received hematopoietic progenitor cell transplantation, which failed due to chronic enteral viral infection and died after gastrointestinal sepsis with septic shock. Conclusion: The early presentation and severity of symptoms should be suspected for timely diagnosis and treatment with a direct impact on the prognosis and quality of life.

Keywords: Severe combined immunodeficiency, T-cell receptor excision circles, lymphopenia.

\footnotetext{
* Servicio de Pediatría Médica.

‡ Departamento de Medicina Basada en la Evidencia. Cochrane México.

$\S$ Médico adscrito al Servicio de Alergia e Inmunología Pediátrica.
} 


\section{INTRODUCCIÓN}

La inmunodeficiencia combinada grave (IDCG) es un error innato del sistema inmune que se caracteriza por defectos en el desarrollo o función de linfocitos T, B y/o NK, predispone a infecciones graves causadas por gérmenes oportunistas como hongos, bacterias o virus, $y$ representa una emergencia pediátrica. ${ }^{1}$

Los pacientes que padecen la enfermedad rara vez sobreviven sin tratamiento después del primer año de vida, lo que obliga a un diagnóstico y tratamiento oportuno. El tratamiento curativo sigue siendo el trasplante de células progenitoras hematopoyéticas (TCPH), con una mayor tasa de sobrevivencia en los primeros cuatro meses de vida. El éxito del TCPH depende de muchos factores: compatibilidad del donador, número y gravedad de las infecciones al momento del diagnóstico previo o durante el TCPH.

Las IDCG se consideran enfermedades raras, la frecuencia varía de 1 en 50,000 a uno en un millón de recién nacidos vivos. La herramienta de tamizaje neonatal con cuantificación de TREC's como parte de un programa piloto en Wisconsin, Estados Unidos, en 2008 a la fecha, estima una incidencia de 1 a 100,000 nacidos vivos. ${ }^{2}$

La Sociedad Latinoamericana de Inmunodeficiencias Primarias (LASID), quien de acuerdo con su base de datos con corte en marzo de 2018, tiene el registro 195 de IDCG en toda Latinoamérica. ${ }^{3}$ En México se desconoce la prevalencia de esta enfermedad. ${ }^{4}$ Sin embargo, considerando el reporte de las «Principales causas de mortalidad infantil en menores de un año» de la Dirección General de Información en Salud con corte en 2016, ${ }^{5}$ las infecciones respiratorias agudas bajas y las enfermedades infecciosas intestinales junto con la septicemia y neumonía figuran dentro de las primeras 10 causas de mortalidad, por lo que deberían considerarse los defectos inmunológicos dentro de los diagnósticos diferenciales.

Las IDCG se deben a mutaciones de alguno de los 17 genes conocidos que codifican componentes del sistema inmunitario cruciales para el desarrollo de linfocitos $\mathrm{T}$, así como de linfocitos $\mathrm{B}$ y NK, caracterizando fenotipos específicos. La más frecuente es IDCG ligado al cromosoma X (por defecto en el gen IL2RG). ${ }^{1}$

Los hallazgos que orientan al diagnóstico son la presencia de infección grave en el primer año de vida, debido a virus, bacterias u hongos, falla para medrar, con/ sin antecedente familiar previo, presencia de linfopenia (<2 DE para edad), niveles normales o bajos de inmunoglobulinas y subpoblaciones de linfocitos con afección de células T, B y/o NK (Tabla 1). Existen herramientas para el tamizaje diagnóstico de las inmunodeficiencias primarias (IDP), como los fragmentos circulares de ácido desoxirribonucleico (ADN) que se producen durante la maduración normal de los linfocitos $\mathrm{T}$, que se denominan TREC's, los cuales no se replican en la mitosis
Tabla 1: Características clínicas y de laboratorio en IDCG.12,13

\begin{tabular}{|c|c|}
\hline Hallazgos clínicos & Hallazgos de laboratorio \\
\hline Infección severa & Linfopenia (<2 DE) \\
\hline Diarrea crónica & Hipogammaglobulinemia \\
\hline Falla para medrar & $\begin{array}{l}\text { Linfocitos B ausentes }(<50 / \mu \mathrm{L}) \\
\text { con títulos de isohemaglutinina } \\
(<1: 8) \text { de inmunoglobulina } \\
\mathrm{M}(\mathrm{IgM}) \text { ausentes y ninguna } \\
\text { respuesta a las inmunizaciones }\end{array}$ \\
\hline $\begin{array}{l}\text { Aumento del gasto energético } \\
\text { basal }\end{array}$ & $\begin{array}{l}\text { Linfocitos T bajos o ausentes } \\
(<300 / \mu \mathrm{L}) \text { con baja respuesta } \\
\text { proliferativa o ausente a mitó- } \\
\text { genos y aloantígenos ( }<10 \% \\
\text { en el extremo inferior del rango } \\
\text { normal en la edad) }\end{array}$ \\
\hline $\begin{array}{l}\text { Tejido linfoide periférico ausente } \\
\text { (amígdalas, adenoides, gan- } \\
\text { glios axilares/inguinales) }\end{array}$ & $\begin{array}{l}\text { Círculos de escisión del } \\
\text { receptor de células T (TREC's) } \\
\text { ausentes o muy bajos }\end{array}$ \\
\hline $\begin{array}{l}\text { Reacciones adversas (infec- } \\
\text { ciones) causadas por vacunas } \\
\text { vivas, como Bacillus Calmette- } \\
\text { Guérin (BCG), rotavirus o } \\
\text { varicela } \\
\text { Ausencia de sombra tímica en } \\
\text { radiografía de tórax }\end{array}$ & \\
\hline
\end{tabular}

celular y siguen, por lo tanto, un patrón de dilución que permite estimar de forma cuantitativa la replicación celular mediante el análisis del ADN, de los linfocitos de sangre periférica y a través de gotas de sangre seca en las tarjetas de Güthrie. Esta determinación permite que se realicen las pruebas confirmatorias desde los primeros días de vida sin esperar a las manifestaciones infecciosas, además, dicho tamizaje ha demostrado ser una prueba económica, sensible y específica para el tamizaje de IDCG. ${ }^{6}$

\section{CASO CLÍNICO}

Lactante de dos meses de edad sin endogamia ni consanguinidad. Producto de segunda gesta, obtenido por vía abdominal, de término. Con una hermana de tres años de edad, sana. Madre de 21 años quien cursó con infección urinaria y cervicovaginitis tratada en el segundo trimestre de gestación.

Recibió inmunización con BGC al nacer sin reacciones adversas.

A los 19 días de vida presentó fiebre de $38.2^{\circ} \mathrm{C}$, de patrón intermitente e hiporexia. Fue tratado con paracetamol, ampicilina y amikacina intravenosa por sepsis tardía con estancia hospitalaria durante cinco días. Al mes de vida reinició con fiebre de $39.2{ }^{\circ} \mathrm{C}$, de patrón 
intermitente, por presentar examen de orina patológico, con urocultivo positivo a Escherichia coli con más de $100,000 \mathrm{UFC} / \mathrm{mL}$, cuyo antibiograma reportó sensibilidad a amikacina con resistencia intermedia. Fue enviado por facultativo para manejo hospitalario.

A la exploración física a su ingreso se observó un paciente eutrófico. Destacaron placas blancas amarillentas en cara interna de mejillas y faringe, con sospecha de extensión a esófago, y eritema en zona del pañal (Figura 1). Se inició terapia antimicrobiana con amikacina y fluconazol. El ultrasonido abdominal reportó cistitis y en la urografía excretora estenosis ureteropiélica con leve ectasia de sistema colector (Figura 2). A las 72 horas de su ingreso persistió febril y se realizó cambio de antibiótico a piperacilina-tazobactam. El urocultivo de control fue negativo.

A pesar de presentar buen estado general, persistió febril, por lo que se solicitó valoración inmunológica. Se sospechó de inmunodeficiencia primaria (IDP) debido a la detención del peso, linfopenia con cuentas entre 350 a $1,500 / \mathrm{mm}^{3}$, anemia microcítica e hipocrómica y ausencia de timo en radiografía de tórax (Figura 1). Se reportaron niveles de inmunoglobulinas séricas bajas para la edad (IgG $100 \mathrm{mg} / \mathrm{dL}$ [206-601 mg/dL] IgA $2.52 \mathrm{mg} / \mathrm{dL}$ [2.8-47 mg/dL] lgE < $1 \mathrm{ku} / \mathrm{L}$ [0.8-3.76 ku/L] lgM $6.1 \mathrm{mg} /$ $\mathrm{dL}$ [17-105 mg/dL]), niveles de complemento C3 y C4 altos para la edad. Para descartar causas posibles de linfopenias se solicitaron serologías para virus de inmunodeficiencia humana $(\mathrm{VIH})$, virus Epstein-Barr, citomegalovirus y complejo TORCH, reportadas negativas. Las

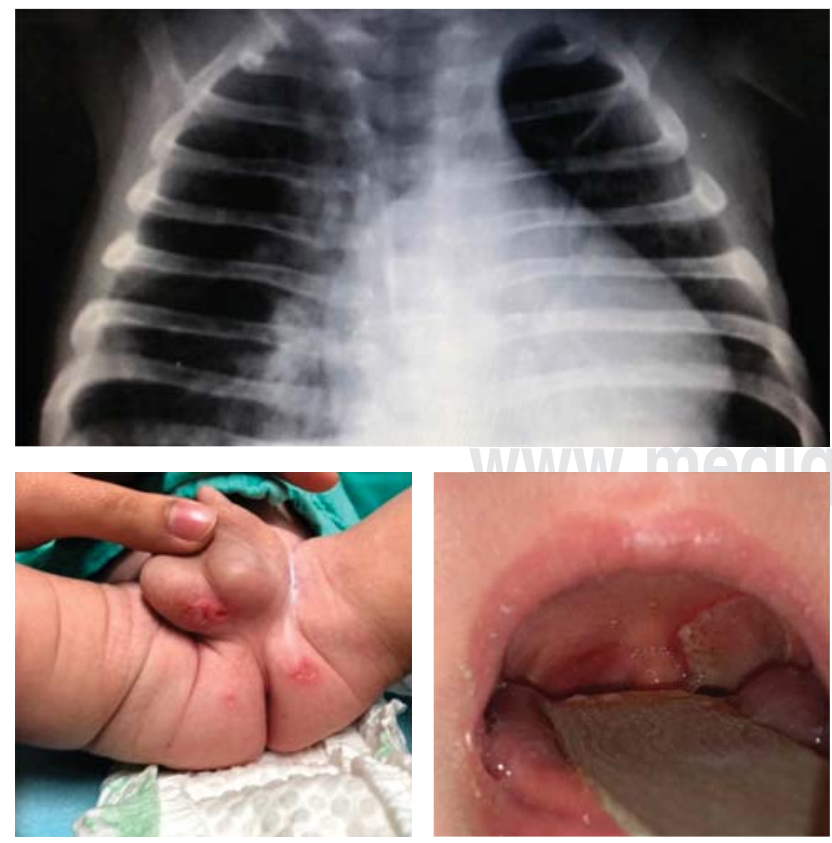

Figura 1: Hallazgos clínicos y radiológicos. subpoblaciones de linfocitos fueron reportadas en 332/ $\mathrm{mm}^{3}$ : linfocitos T (CD 3+) de 4\% [53-84\%], linfocitos B (CD19): 0\% [16-32\%] y natural killer (CD 16/56) 85\%, compatible con fenotipo T- B- NK+, se realizó tamiz neonatal ampliado de 76 elementos con reporte de TREC's positivo para IDCG. Por el antecedente de vacunación con Bacillus Calmette-Guérin (BCG) se realizó baciloscopia en jugo gástrico, la cual se reportó negativa.

Confirmado el diagnóstico, se inició tratamiento con GGIV a $1 \mathrm{~g} / \mathrm{kg} /$ dosis cada 21 días, profilaxis antimicrobiana con trimetoprim-sulfametoxazol ( $5 \mathrm{mg} / \mathrm{kg} / \mathrm{día})$, fluconazol ( $5 \mathrm{mg} / \mathrm{kg} / \mathrm{día}$ ) e isoniazida. Por el fenotipo celular se sospechó de mutación en los genes RAG1/ RAG2 versus Artemis, que cursan con radiosensibilidad y se determinó el uso de hemoderivados filtrados y radiados para disminuir el riesgo de enfermedad injerto versus hospedero, alimentación con hidrolizado extenso de proteínas, debido al alto riesgo de desarrollar diarrea, malabsorción, inflamación intestinal y falla para medrar. ${ }^{7}$ Se refirió a tercer nivel de atención para realización de TCPH con donador haploidéntico a la brevedad posible, ya que no se encontraron donadores relacionados $100 \%$ compatibles.

A los cuatro meses de edad se realizó TCPH haploidéntico materno, con movilización de células progenitoras hematopoyéticas (CD34+) a sangre periférica con una dosis de $8 \times 106$ células CD34+/kg de peso del paciente; sin embargo, desarrolló una infección gastrointestinal por norovirus, lo que causó falla primaria al injerto con un quimerismo al día 30 post-TCPH sin evidencia de células del donador. Se planteó la posibilidad de un segundo TCPH; no obstante, en los meses posteriores presentó gastroenteritis y perforación intestinal que ameritó laparotomía exploratoria con resección intestinal extensa, requirió de manejo en terapia intensiva en donde falleció por choque séptico.

\section{DISCUSIÓN}

La inmunodeficiencia combinada grave es un síndrome poco frecuente, mortal sin tratamiento, que tiene diversas causas genéticas, en el que existe ausencia combinada de las funciones de los linfocitos $T$ y los linfocitos $B$, y en muchos casos también de las células natural killer. Estos defectos predisponen a infecciones graves, por lo que las manifestaciones clínicas consisten en fiebre persistente, infecciones a cualquier nivel y falla para medrar.

Es importante considerar las herramientas para el tamizaje y diagnóstico a edades tempranas, antes de la aparición de las manifestaciones clínicas e infecciones que impactan de forma directa en la morbimortalidad de los pacientes con IDCG.

Marciano y colaboradores reportaron, en 2014, 51\% de efectos adversos a la aplicación de BCG en pacientes con IDCG, con una relación directa al conteo abso- 
Vol. 29, Núm. 1・Enero-Abril 2020
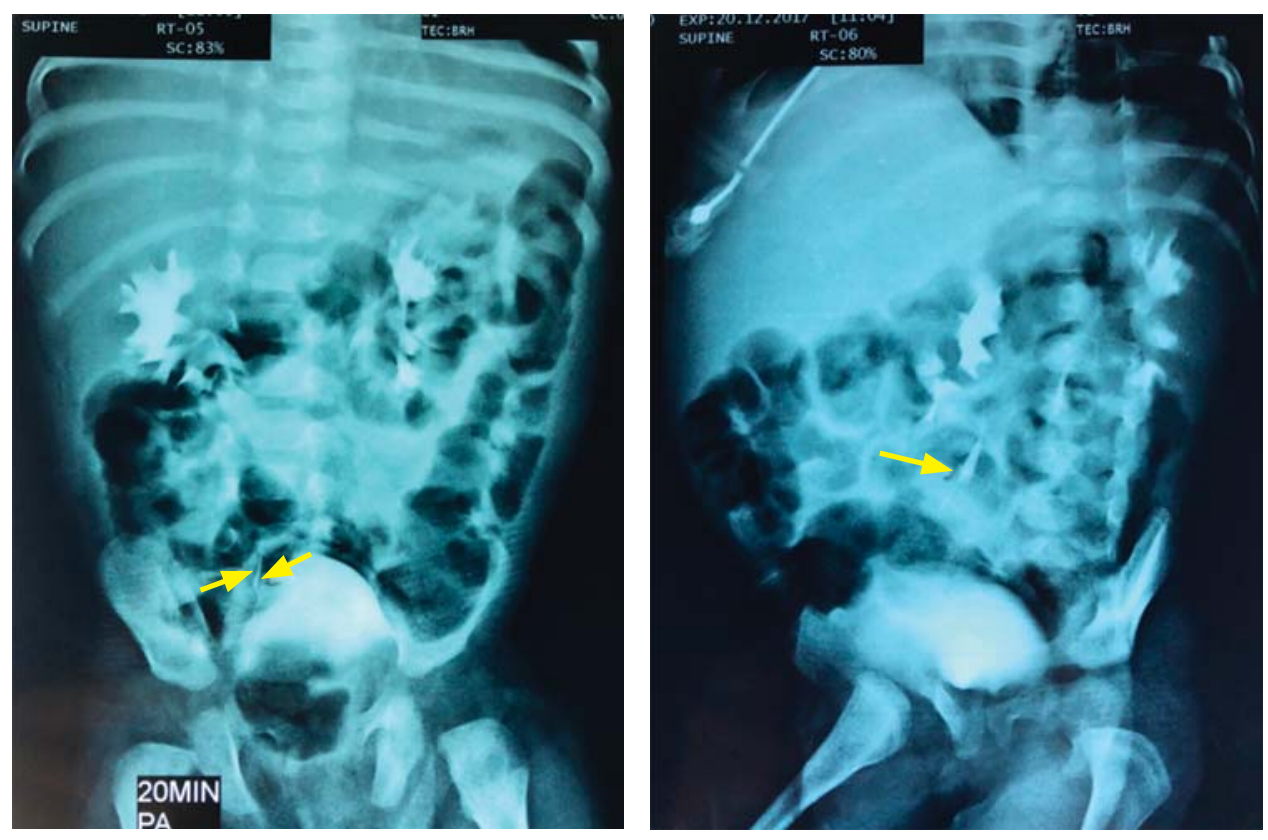

Figura 2:

Estenosis de unión ureteropiélica del lado derecho, la cual está provocando dilatación de la pelvis renal.

luto de células $\mathrm{T}(<250 / \mu \mathrm{L})$ al momento del diagnóstico, así como la edad al momento de la aplicación (< 1 mes de edad), concluyendo que debería aplazarse al mes de edad o saber el estado inmunológico de los pacientes. ${ }^{8}$

En 2018, Saucedo y su equipo determinaron el tiempo de retraso diagnóstico (considerado desde la fecha de nacimiento hasta la edad de diagnóstico) de 5.5 meses, con un valor mínimo de un mes y un máximo de nueve meses en más de $50 \%$ de los casos, ${ }^{9}$ lo cual ha permitido la implementación de herramientas para evitar dicho retraso.

Una revisión sistemática, llevada a cabo en 2015 por Van der Sek y su grupo, evaluó el rendimiento diagnóstico de los algoritmos publicados para la determinación de TREC's como tamizaje del recién nacido, demostrando una sensibilidad de $100 \%$ de la determinación de TREC's para sospecha diagnóstica de IDCG. ${ }^{10}$

Por otra parte, la reconstitución inmune mediante el TCPH es el tratamiento de elección para este padecimiento. Una cohorte prospectiva publicada en 2017 llevada a cabo por Heimall y socios que incluyeron 118 pacientes diagnosticados antes de los cuatro meses de vida, sometidos a TCPH demostró una tasa de supervivencia a los dos años de 90\% (IC 95\%, 80-95\%). Además, establecen como impacto negativo una infección activa y un diagnóstico tardío de la enfermedad para el éxito del tratamiento. ${ }^{11}$

El caso que presentamos tuvo dificultad en el diagnóstico, debido a que se demostró infección urinaria con aislamiento de germen y malformación urinaria, lo que explicaría la persistencia de la fiebre, así como la aplicación de BCG al nacer sin efectos adversos. Sin embar- go, ante la falla de la ganancia ponderal, persistencia de la fiebre e infecciones oportunistas, se hizo la sospecha con la determinación de niveles séricos bajos de inmunoglobulinas, con medición de TREC's con sospecha de IDCG y confirmando con subpoblaciones de linfocitos, permitiendo la posibilidad de un TCPH haploidéntico que tuvo un desenlace fatal, el cual sigue a muchos de los casos descritos en la literatura, por complicaciones infecciosas previas y posteriores al $\mathrm{TCPH}$, a pesar de haber realizado los diagnósticos a los dos meses de edad y trasplante a los cuatro meses.

\section{CONCLUSIÓN}

El caso demuestra la urgencia pediátrica de esta enfermedad y de conocer las manifestaciones clínicas tempranas que permitan la sospecha diagnóstica, haciendo uso de todas las herramientas disponibles para su confirmación, como la medición de TREC's antes de presentar infecciones graves. En México, no se ha establecido en el sistema de salud a pesar de que las revisiones sistemáticas están a favor de su implementación. Esta herramienta puede brindar la oportunidad de aportar datos fidedignos para tener una incidencia de la IDCG en México.

\section{BIBLIOGRAFÍA}

1. Picard C, Bobby Gaspar H, Al-Herz W, Bousfiha A, Casanova JL, Chatila T et al. International Union of Immunological Societies: 2017 Primary Immunodeficiency Diseases Committee Report on Inborn Errors of Immunity. J Clin Immunol. 2018; 38 (1): 96-128. 
Vol. 29, Núm. 1 • Enero-Abril 2020

2. Kwan A, Abraham RS, Currier R, Brower A, Andruszewski $\mathrm{K}$, Abbott $\mathrm{JK}$ et al. Newborn screening for severe combined immunodeficiency in 11 screening programs in the United States. JAMA. 2014; 312 (7): 729-738.

3. Sociedad Latinoamericana de Immunodeficiencias. Estatísticas-Registro de IDPs. Febrero, 2018. Disponible en: https://registrolasid.org/docs/Estatisticas_LASID-2018_ Marco.pdf

4. Coria-Ramírez E, Espinosa-Padilla S, Espinosa-Rosales F, Vargas-Camaño ME, Blancas-Galicia L. Panorama epidemiológico de las inmunodeficiencias primarias en México. Rev Alerg Mex. 2010; 57 (5): 159-163.

5. INEGI. Principales causas de mortalidad por residencia habitual, grupos de edad y sexo del fallecido. Marzo 2018. Disponible en: http://www.inegi.org.mx/est/contenidos/ proyectos/registros/vitales/mortalidad/tabulados/ ConsultaMortalidad.asp

6. Walkovich K, Connelly JA. Primary immunodeficiency in the neonate: Early diagnosis and management. Semin Fetal Neonatal Med. 2016; 21 (1): 35-43. doi: 10.1016/j. siny.2015.12.005.

7. Smith C, McCabe H, Macdonald S, Morrison L, Prigg R, Trace $S$ et al. Improved growth, tolerance and intake with an extensively hydrolysed peptide feed in infants with complex disease. Clin Nutr. 2018; 37 (3): 1005-1012.

8. Marciano BE, Huang CY, Joshi G, Rezaei N, Carvalho BC, Allwood $Z$ et al. J BCG vaccination in patients with severe combined immunodeficiency: complications, risks, and vaccination policies. Allergy Clin Immunol. 2014; 133 (4): 1134-1141. doi: 10.1016/j.jaci.2014.02.028.
9. Saucedo A, Espinosa S, González M. Inmunodeficiencias combinadas graves ¿enfermedades raras o subregistradas? Rev Aler Mex. 2018; 27 (2): 37-43.

10. Van der Spek J, Groenwold $\mathrm{RH}$, van der Burg M, van Montfrans JM. TREC based newborn screening for severe combined immunodeficiency disease: a systematic review. J Clin Immunol. 2015; 35 (4): 416-430. doi: 10.1007/s10875015-0152-6.

11. Heimall J, Logan BR, Cowan MJ, Notarangelo LD, Griffith LM, Puck JM et al. Immune reconstitution and survival of 100 SCID patients post-hematopoietic cell transplant: a PIDTC natural history study. Blood. 2017; 130 (25): 2718-2727. doi: 10.1182/blood-2017-05-781849.

12. Griffith LM, Cowan MJ, Notarangelo LD, Puck JM, Buckley $\mathrm{RH}$, Candotti $\mathrm{F}$ et al. Improving cellular therapy for primary immune deficiency diseases: recognition, diagnosis, and management. J Allergy Clin Immunol. 2009; 124 (6): 115260.e12. doi: 10.1016/j.jaci.2009.10.022.

13. Barron MA, Makhija M, Hagen LE, Pencharz P, Grunebaum $E$, Roifman CM. Increased resting energy expenditure is associated with failure to thrive in infants with severe combined immunodeficiency. J Pediatr. 2011; 159 (4): 628632.e1. doi: 10.1016/j.jpeds.2011.03.041.

Dirección para correspondencia:

Dr. José Guillermo Pérez Murguía

Cel: 3122100155

E-mail: murguia_jose@ucol.mx 